\title{
Novel properties of photofermentative biohydrogen production by purple bacteria Rhodobacter sphaeroides: effects of protonophores and inhibitors of responsible enzymes
}

Lilit Gabrielyan ${ }^{1,2}$, Harutyun Sargsyan ${ }^{1}$ and Armen Trchounian ${ }^{1 *}$

\begin{abstract}
Background: Biohydrogen $\left(\mathrm{H}_{2}\right)$ production by purple bacteria during photofermentation is a very promising way among biological $\mathrm{H}_{2}$ production methods. The effects of protonophores, carbonyl cyanide $m$-chlorophenylhydrazone (CCCP), 2,4-dinitrophenol (DNP), and inhibitors of enzymes, involved in $\mathrm{H}_{2}$ metabolism, metronidazole (Met), diphenyleneiodonium (DPI), and dimethylsulphoxide (DMSO) on $\mathrm{H}_{2}$ production by Rhodobacter sphaeroides MDC6522 isolated from Jermuk mineral springs in Armenia have been investigated in both nitrogen-limited and nitrogen-excess conditions.

Results: With the increase of inhibitors concentrations $\mathrm{H}_{2}$ yield gradually decreased. The complete inhibition of $\mathrm{H}_{2}$ production was observed in the presence of DPI and CCCP. DPI's solvent-DMSO in low concentration did not significantly affect $\mathrm{H}_{2}$ yield. $N_{\text {, }} \mathrm{N}^{\prime}$-dicyclohexylcarbodiimide (DCCD)-inhibited the $\mathrm{F}_{0} \mathrm{~F}_{1}$-ATPase activity of bacterial membrane vesicles was analyzed in the presence of inhibitors. Low concentrations of DPI and DMSO did not affect ATPase activity, whereas Met and CCCP stimulated enzyme activity. The effect of DNP was similar to CCCP.

Conclusions and significance: The results have shown the low concentration or concentration dependent effects of protonophores and nitrogenase and hydrogenase inhibitors on photofermentative $\mathrm{H}_{2}$ production by $\mathrm{Rh}$. sphaeroides in nitrogen-limited and nitrogen-excess conditions. They would be significant to understand novel properties in relationship between nitrogenase, hydrogenase and the $\mathrm{F}_{0} \mathrm{~F}_{1}$-ATPase in $R$. sphaeroides, and regulatory pathways of photofermentation. The inhibitors of nitrogenase and hydrogenase can be used in biotechnology for regulation of $\mathrm{H}_{2}$ production in different technology conditions and development of scale-up applications, for biomass and energy production using purple bacterial cells.
\end{abstract}

Keywords: Rhodobacter sphaeroides, Biohydrogen photoproduction, Protonophores, Nitrogenase and hydrogenase inhibitors, ATPase activity

\section{Background}

Over the next 50 years biofuels [biohydrogen $\left(\mathrm{H}_{2}\right)$, ethanol, and bio-methane] will be one of the most

\footnotetext{
*Correspondence: trchounian@ysu.am

1 Department of Microbiology \& Microbes and Plants Biotechnology, Biology Faculty, Yerevan State University, 1 A. Manoukian Str., 0025 Yerevan, Armenia

Full list of author information is available at the end of the article
}

promising ways of energy supply. $\mathrm{H}_{2}$ is a very effective alternative energy source, because it produces high amount of energy $(\sim 140 \mathrm{MJ} / \mathrm{kg})$, which is as least 3 times greater, than natural gas and hydrocarbon fuels [1-3]. $\mathrm{H}_{2}$ is considered as an environmentally friendly fuel, its combustion does not contribute the air contamination as there is no production of carbon dioxide, the only product of the reaction is water (Fig. 1) $[1,2,4,5]$. Now, the 


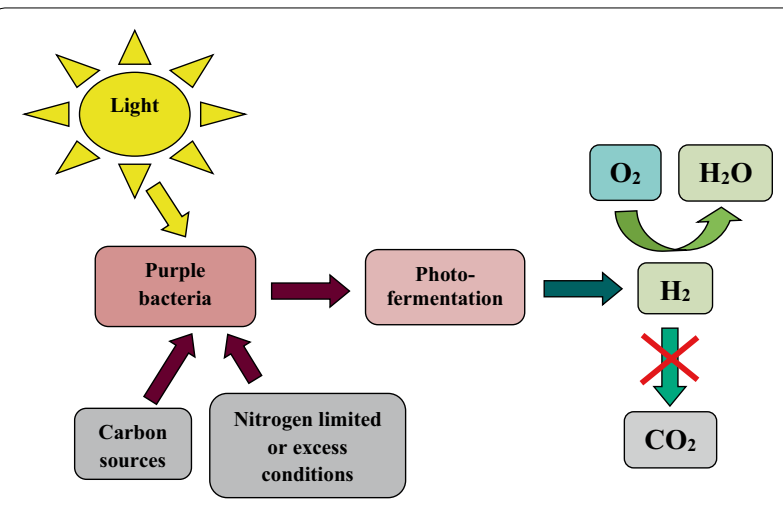

Fig. $1 \mathrm{H}_{2}$ production by purple bacteria during photofermentation of carbon sources and under light

world production of $\mathrm{H}_{2}$ is more than 50 million tons, and it is increased quickly over the world, it will decrease $\mathrm{H}_{2}$ production costs, which can be competitive with other fuels, such as oil and natural gas [3]. Thus, shortly $\mathrm{H}_{2}$ can become one of the main fuels in global energy economy.

In comparison with the traditional ways of $\mathrm{H}_{2}$ production such as thermochemical and photochemical processes, biological $\mathrm{H}_{2}$ production is known to be less energy intensive, because it carried out at ambient temperature and atmospheric pressure $[2,3] . \mathrm{H}_{2}$ can be produced (1) by chemotroph bacteria during "dark" or "mixed-acid" fermentation of various carbon sources; (2) by microalgae and cyanobacteria during "direct" and "indirect" biophotolysis, resulting in water splitting, and (3) by purple bacteria during "photofermentation" of organic carbon substrates using sunlight as energy source (Fig. 1) [1-3, 6-8]. Among these, purple bacteria are highly favorable microorganisms for $\mathrm{H}_{2}$ production. Photosynthetic purple non-sulfur bacteria are able to produce $\mathrm{H}_{2}$ during photofermentation of organic carbon sources under anaerobic conditions using light as energy source [7-9]. As known, two types of enzymes-nitrogenase and hydrogenase are involved in photofermentative $\mathrm{H}_{2}$ metabolism in purple bacteria [2, 7, 8]. Purple nonsulfur bacterium Rhodobacter sphaeroides contains only one form of nitrogenase - [Mo-Fe]-nitrogenase [7, 8]; this is a binary enzyme, consisting of two metalloproteins: [Fe]-protein and [Mo-Fe]-protein [2, 10, 11]. These bacteria also contain [Ni-Fe]-hydrogenases, which are classified according to their involving in $\mathrm{H}_{2}$ metabolism: " $\mathrm{H}_{2}$-evolving", " $\mathrm{H}_{2}$-uptake" and "bidirectional" hydrogenases [1,11-13]. The latter can catalyse $\mathrm{H}_{2}$ uptake or production depending on the growth conditions.

During photofermentation purple bacteria can oxidize some organic carbon substrates to $\mathrm{CO}_{2}$, protons and electrons in tricarboxylic acid cycle (TCA) by generating
NADH $[7,8]$. The protons are pumped through the bacterial membrane during the photosynthetic electron transport with generation of proton motive force $(\Delta p)$. Under nitrogen-limited conditions or in the absence of $\mathrm{N}_{2}$, upon light $\mathrm{H}_{2}$ production by purple bacteria is mainly mediated by nitrogenase, which catalyzes conversion of protons to $\mathrm{H}_{2}$ by using energy from ATP, which is generated via the proton-translocating $\mathrm{F}_{\mathrm{O}} \mathrm{F}_{1}$-ATPase; while hydrogenases in Rh. sphaeroides are usually involved in $\mathrm{H}_{2}$ uptake. But these hydrogenases can be reversible depending on the conditions: the reversibility of hydrogenases might be similar to the situation with hydrogenases in Escherichia coli or cyanobacteria [1, 3, 8, 13].

Carbonyl cyanide $m$-chlorophenylhydrazone (CCCP) and 2,4-dinitrophenol (DNP), protonophores functioning as uncouplers and dissipating $\Delta p$, and metronidazole (Met), a low-range electron acceptor (redox potential $\left(E_{h}\right)$ is equal to $-325 \mathrm{mV}$ ), have been shown to inhibit nitrogenase activity in cyanobacteria [14-20]. Diphenyleneiodonium (DPI) was established as an inhibitor of hydrogenase activity in Rh. capsulatus and Chlamydomonas reinhardtii [21, 22]. Dimethylsulphoxide (DMSO) (solvent of DPI) affected the bacterial growth properties and membrane stability [23, 24]. In our previous works, we demonstrated the inhibitory effects of high concentrations of DPI, DMSO and Met on $\mathrm{H}_{2}$ production by $R$. sphaeroides strain MDC6521 isolated from Arzni mineral springs in Armenia [25, 26]. The hydrogenase activity in Rh. sphaeroides and its relationship with nitrogenase and the $\mathrm{F}_{\mathrm{O}} \mathrm{F}_{1}$-ATPase were suggested. Moreover, light and dark alternations affected $\mathrm{H}_{2}$ production by $R h$. sphaeroides [9]. However, there are no data on effects of protonophores and those inhibitors at low concentrations on $\mathrm{H}_{2}$ production ability of $R h$. sphaeroides. It is known, that many chemicals show biological effects at low and ultra-low concentrations [27, 28]. This is very interesting phenomenon; however, the mechanisms of low and ultralow concentrations effects are not clear. It is interesting, how the effects of compounds used in low concentrations differ from those of relatively high concentrations and for other bacterial strains. Appropriate mechanisms of photofermentation and $\mathrm{H}_{2}$ production are still not clear; further studies will be needed.

In the present study we have investigated the effects of protonophores such as CCCP, DNP, inhibitors of nitrogenase and hydrogenase such as Met, DPI, and DMSO at different concentrations on $\mathrm{H}_{2}$ production ability depending on the nitrogen-limited and nitrogen-excess conditions in Rh. sphaeroides strain MDC6522, isolated from the other mineral springs in Armenian mountains-Jermuk. Novel and significant experimental data about the concentration-dependent effects of protonophores and inhibitors of nitrogenase and hydrogenase in 
$R h$. sphaeroides have been obtained. The results would improve our understanding of mechanisms, regulatory pathways of bacterial $\mathrm{H}_{2}$ metabolism and bioenergetics of photofermentation. They can be helpful for determining the role of various enzymes and the interaction between them in $\mathrm{H}_{2}$ production depending on the growth conditions. Thus they might lead to optimization of the technology conditions for efficient $\mathrm{H}_{2}$ production. Importantly, the effects might be applied in $\mathrm{H}_{2}$ biotechnology, energy production using purple bacteria.

\section{Results}

\section{Effect of various inhibitors on $R h$. sphaeroides growth} properties

Photofermentative $\mathrm{H}_{2}$ production by purple non-sulfur bacteria is known to be catalyzed by nitrogenase and hydrogenase. During the photosynthetic electron transport protons are pumped through the membrane with generation of $\Delta p$, which is used to generate ATP via the $\mathrm{F}_{\mathrm{O}} \mathrm{F}_{1}$-ATPase and to transfer electrons to ferredoxin (Fd). It is known that then Fd and ATP are used to generate $\mathrm{H}_{2}$ via nitrogenase $[2,7,8]$. As it was shown in our previous papers $[25,26], \mathrm{H}_{2}$ production was strongly inhibited by high concentrations of DPI and Met. The effect of various compounds such as hydrogenase inhibitor DPI and its solvent DMSO, nitrogenase inhibitor Met, protonophore CCCP and their concentrations on growth peculiarities and photofermentative $\mathrm{H}_{2}$ production by $R h$. sphaeroides strain MDC6522, in comparison with the other strain MDC6521, isolated from Arzni mineral springs, was studied.

The growth properties were determined during anaerobic growth of $R h$. sphaeroides MDC6522 upon illumination. The compounds used affected the specific growth rate of bacterial culture. Figure 2 shows a comparison of the growth specific rates of $R h$. sphaeroides, grown in the presence of different inhibitors. With the increase of reagents concentrations, the specific growth rate gradually decreased. 1-2 $\mu \mathrm{M}$ DPI decreased the specific growth rate 6 - to 12 -folds ( $\mathrm{p}<0.001$ ), whereas $1 \mathrm{mM}$ Met suppressed growth rate $\sim 5$-fold ( $\mathrm{p}<0.001$ ) (see Fig. 2). $R h$. sphaeroides was unable to grow in the medium with CCCP and DNP, and both uncouplers were added after $24 \mathrm{~h}$ growth of culture, after then bacterial growth was strongly inhibited (not shown). The effect of DPI's solvent DMSO on the culture specific growth rate was also studied for revealing the inhibitory effect of DPI. In culture with $1 \mathrm{mM}$ DMSO this rate was 1.3 -fold $(\mathrm{p}<0.01)$ lower than that of the control, whereas 5-10 mM DMSO suppressed the specific growth rate $\sim 1.5$ - to 2 -folds $(\mathrm{p}<0.01$ ) in comparison with the control (Fig. 2). These data were similar to the results on DPI and DMSO effects obtained

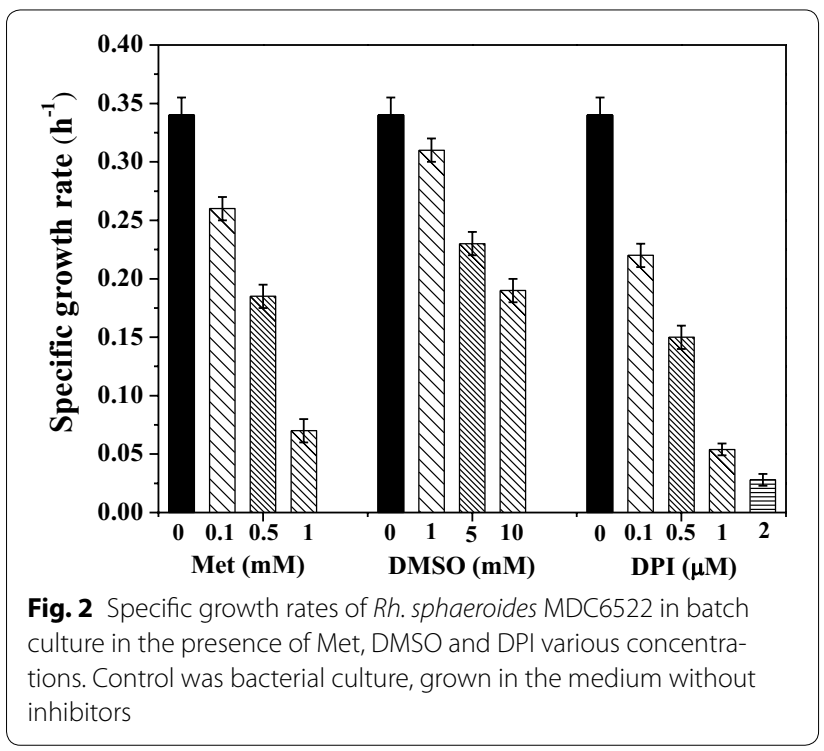

for the other strain MDC6521 [26], but Rh. sphaeroides MDC6521 was more sensitive to the inhibitors used.

\section{Effect of various inhibitors for enzymes on medium $\mathrm{pH}$ and $E_{h}$ during $R h$. sphaeroides anaerobic growth}

The growth medium $\mathrm{pH}$ is an important parameter for bacterial growth under different conditions [9, 2931]. During the anaerobic growth of $R h$. sphaeroides MDC6522 control cells up to $72 \mathrm{~h}$ in nitrogen-limited anaerobic conditions, the $\mathrm{pH}$ of medium has risen from $7.0 \pm 0.2$ (initial pH) up to 8.8 (Fig. 3a). This increase can be caused by the carbon source utilization and $\mathrm{OH}^{-}$ ions efflux or by the polyhydroxybutyrate formation [29]. After then, during growth up to $96 \mathrm{~h}, \mathrm{pH}$ decreased, which can be caused by the generation of photofermentation end-products, particularly acids, which could decay with $\mathrm{H}_{2}$ evaluation. Also during $\mathrm{H}_{2}$ generation the coevolved $\mathrm{CO}_{2}$ can moderate $\mathrm{pH}$ change.

All inhibitors affected the $\mathrm{pH}$ of culture growth medium (Fig. 3). The $\mathrm{pH}$ value increased to $\sim 9.0$ by addition of 5-10 $\mu \mathrm{M}$ DNP (after $24 \mathrm{~h}$ growth) (Fig. 3a). The other kinetics of $\mathrm{pH}$ was observed by the addition of CCCP (after $24 \mathrm{~h}$ growth): $\mathrm{pH}$ increased to $\sim 7.8-8.0$ in the presence of $0.5-1 \mu \mathrm{M} C C C P$, whereas in the presence of $2 \mu \mathrm{M}$ CCCP and $50 \mu \mathrm{M}$ DNP pH of medium was not changed (see Fig. 3a). In the presence of $0.5-1 \mu \mathrm{M}$ DPI the $\mathrm{pH}$ of medium was not changed much, and it decreased to $\sim 6.7$ in medium with $2 \mu \mathrm{M}$ DPI (Fig. 3b). By addition of 1-5 mM DMSO $\mathrm{pH}$ changes during bacterial growth were similar to the control, and $\mathrm{pH}$ was not changed much in the presence of $10 \mathrm{mM}$ DMSO (see Fig. 3b). In the presence of Met $\mathrm{pH}$ change during $R h$. 

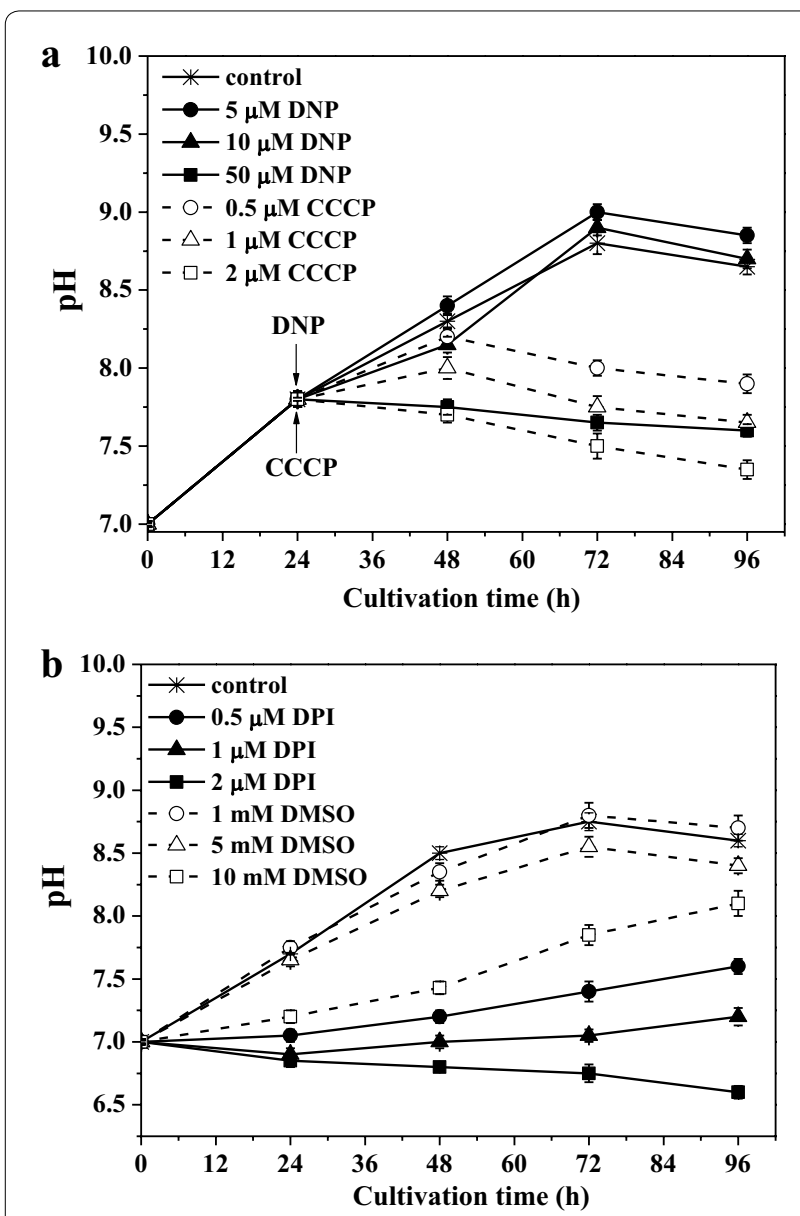

Fig. 3 The effects of DNP and CCCP (a), DPI and DMSO (b) various concentrations on medium pH during Rh. sphaeroides MDC6522 anaerobic growth in batch culture upon illumination. DNP and CCCP were added after $24 \mathrm{~h}$ bacterial growth

sphaeroides anaerobic growth was similar to the control (not shown).

Redox potential $\left(E_{h}\right)$ is another significant parameter of the bacterial growth medium, which can be determined as the ability of a biological system to oxidize or reduce different substrates [9, 31-33]. According to the Nernst equation $E_{h}$ depends on the reduced and oxidized products of fermentation, as well as on $\mathrm{pH}$ [29-31]. $E_{h}$ of Rh. sphaeroides MDC6522 control cells decreased to $-650 \pm 20 \mathrm{mV}$ during growth up to $72 \mathrm{~h}$ in nitrogen-limited anaerobic conditions (Fig. 4a). In the medium with $5 \mu \mathrm{M}$ DNP $E_{h}$ decreased to $-580 \pm 20 \mathrm{mV}$; whereas with $50 \mu \mathrm{M}$ DNP $E_{h}$ dropped to $-170 \pm 10 \mathrm{mV}$ only (see Fig. 4a). In contrast to DNP, the other protonophore-CCCP delayed drop in $E_{h}$. The inhibition of bacterial growth may arise from the effect of CCCP $(1-2 \mu \mathrm{M})$ on $E_{h}$, which was decreased to $-315 \pm 20$
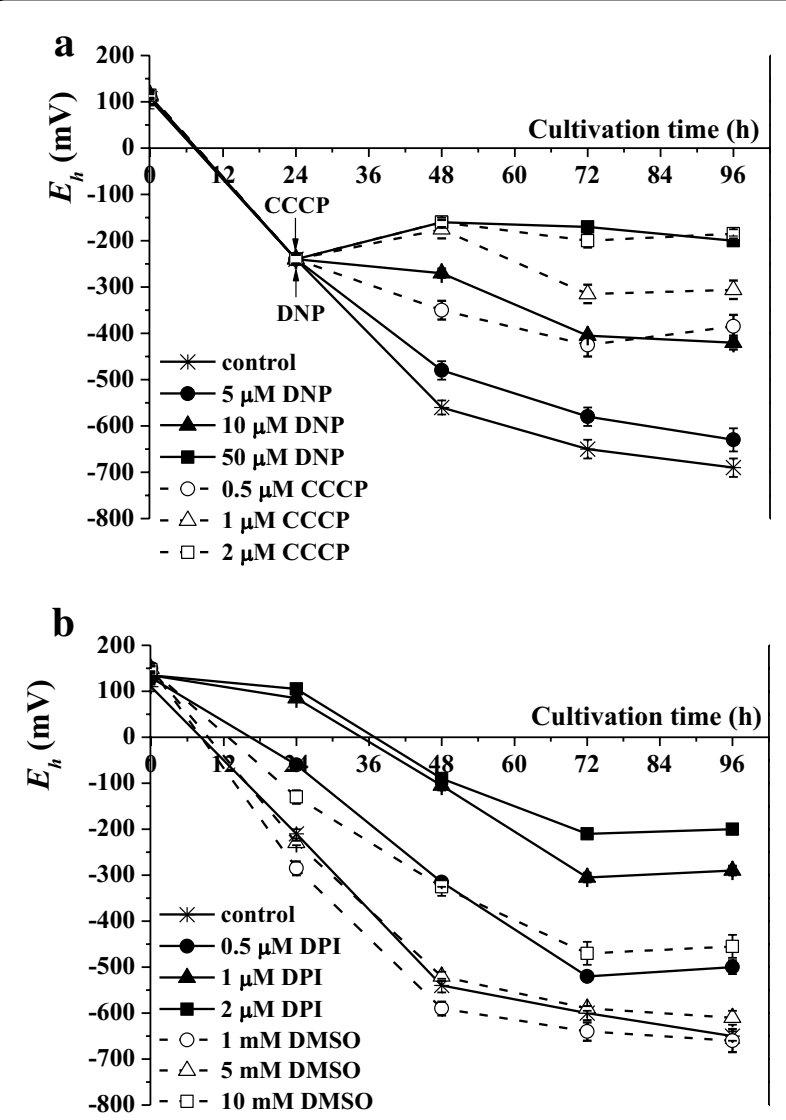

Fig. 4 The effects of DNP and CCCP (a), DPI and DMSO (b) various concentrations on medium $E_{h}$ during Rh. sphaeroides MDC6522 anaerobic growth in batch culture upon illumination. DNP and CCCP were added after $24 \mathrm{~h}$ bacterial growth

and $-200 \pm 15 \mathrm{mV}$, respectively, during $72 \mathrm{~h}$ culture growth (see Fig. 4a). In the medium with $0.5 \mathrm{mM}$ Met $E_{h}$ decreased to $-410 \pm 5 \mathrm{mV}$; whereas with $1 \mathrm{mM}$ Met $E_{h}$ dropped to $-210 \pm 10 \mathrm{mV}$ only (not shown). Therefore, the used compounds affect the $E_{h}$ in a concentrationdependent manner. Change of $E_{h}$ can be caused by indirect effect of these reagents on $E_{h}$, or by redox processes on a surface of bacterial membrane. Thus, the negative values of $E_{h}$ and reduced medium are required for bacterial growth.

$E_{h}$ of $R h$. sphaeroides str. MDC6522 control cells, grown in nitrogen-excess anaerobic conditions up to $72 \mathrm{~h}$, decreased to $-600 \pm 15 \mathrm{mV}$ (Fig. 4b). The addition of DPI into the growth medium also affected $E_{h}$ : in the medium with $0.5 \mu \mathrm{M}$ DPI $E_{h}$ decreased to $-520 \pm 10 \mathrm{mV}$; whereas with $2 \mu \mathrm{M}$ DPI $E_{h}$ did not change much (Fig. $4 \mathrm{~b}$ ). $1 \mathrm{mM}$ DMSO increased $E_{h}$ up to $-640 \pm 20 \mathrm{mV}$. At the same time $E_{h}$ gradually decreased during the growth from 5 to $10 \mathrm{mM}$ DMSO: $E_{h}$ drop was more intensive in 
the presence of $10 \mathrm{mM}$ DMSO (up to $-470 \pm 25 \mathrm{mV}$ ) (see Fig. 4b).

\section{Effect of various inhibitors for enzymes on $\mathrm{H}_{2}$} photoproduction during $R h$. sphaeroides anaerobic growth The analysis of $E_{h}$ changes gives information not only on main redox processes but also on $\mathrm{H}_{2}$ yield during bacterial anaerobic growth. There is a direct relationship between changes of $E_{h}$ and $\mathrm{H}_{2}$ production by these bacteria; the reduction of protons to $\mathrm{H}_{2}$ is observed under strong reducing conditions $[9,31,32,34]$.

$\mathrm{H}_{2}$ yield of Rh. sphaeroides MDC6522 control cells during growth up to $72 \mathrm{~h}$ in nitrogen-limited anaerobic conditions was $6.91 \mathrm{mmol}_{2}$ (g dry weight $\left.(\mathrm{DW})\right)^{-1}$, whereas in nitrogen-excess conditions $\mathrm{H}_{2}$ yield was $\sim 1.2-$ fold lower (Fig. 5). As it can be seen from Fig. 5, four reagents used, except 1-5 mM DMSO, inhibited $\mathrm{H}_{2}$ production by $R h$. sphaeroides. With the increase of inhibitors concentrations, the $\mathrm{H}_{2}$ yield gradually decreased. By addition of 0.1 and $0.5 \mathrm{mM} \mathrm{Met} \mathrm{H}_{2}$ yield has decreased $\sim 1.6$-fold $(\mathrm{p}<0.01)$ and $\sim 7.6$-fold $(\mathrm{p}<0.001)$, respectively (see Fig. 5). The effect of Met on $\mathrm{H}_{2}$ yield might be coupled with change of photosynthetic electron transfer with Met as a preferred acceptor of electrons, instead of nitrogenase.

CCCP and DNP are two well-known protonophores, which are used to dissipate proton gradient responsible for ATP generation via the $\mathrm{F}_{\mathrm{o}} \mathrm{F}_{1}$-ATPase and to uncouple photophosphorylation from photosynthetic electron transfer [35]. The Fig. 5 shows the $\mathrm{H}_{2}$ yield level in the presence of various concentrations of CCCP and DNP. In medium with $1-2 \mu \mathrm{M} \mathrm{CCCP} \mathrm{H}_{2}$ production by

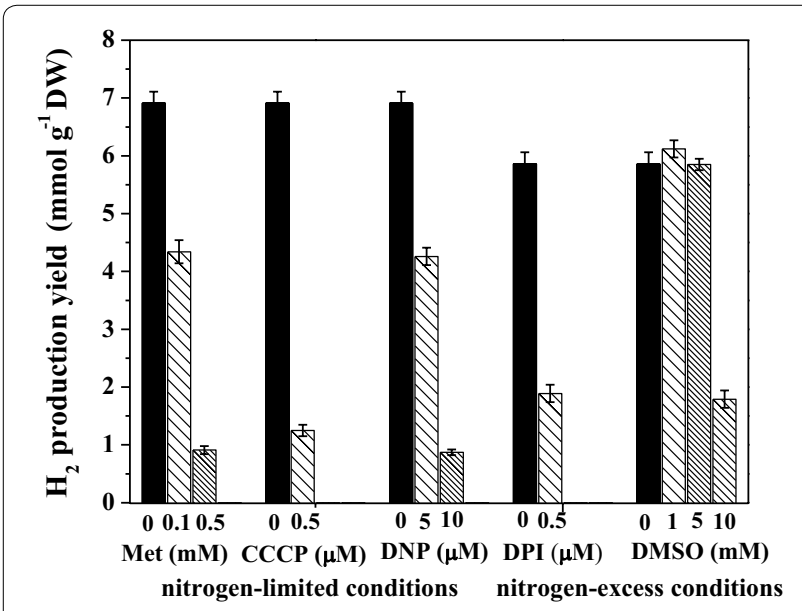

Fig. 5 The effects of inhibitors various concentrations on $\mathrm{H}_{2}$ yield of $R h$. sphaeroides MDC6522 during anaerobic growth in batch culture up to $72 \mathrm{~h}$. The $\mathrm{H}_{2}$ yield was calculated by decrease in $E_{h}$ (see "Methods") bacterium has not been observed during $72 \mathrm{~h}$ growth, and has decreased $\sim 5.5$-fold $(\mathrm{p}<0.001)$ in the presence of $0.5 \mu \mathrm{M}$ CCCP (see Fig. 5). $\mathrm{H}_{2}$ yield lowered $\sim 1.6$-fold ( $\mathrm{p}<0.01$ ) and $~ 8.0$-fold $(\mathrm{p}<0.001)$ in the medium with 5 and $10 \mu \mathrm{M}$ DNP, and was not observed in the presence of $50 \mu \mathrm{M}$ DNP. It is suggested that protonophores can decrease $\mathrm{H}_{2}$ generation by inhibiting of ATP synthesis by photophosphorylation, which is significant for nitrogenase-dependent photofermentative $\mathrm{H}_{2}$ production. These data were similar to the results obtained by Skizim and co-workers for cyanobacteria Cyanothece [35].

In medium with 1-2 $\mu \mathrm{M}$ DPI, the production of $\mathrm{H}_{2}$ by $R h$. sphaeroides has not been observed during $72 \mathrm{~h}$ growth, and has decreased $\sim 3.1$-fold $(\mathrm{p}<0.001)$ by addition of $0.5 \mu \mathrm{M}$ DPI in comparison with the control (see Fig. 5). As shown in Fig. 5, DPI's solvent-DMSO in concentrations of $1-5 \mathrm{mM}$ did not affect $\mathrm{H}_{2}$ production by $R h$. sphaeroides, whereas the high concentrations $(10 \mathrm{mM})$ suppressed the $\mathrm{H}_{2}$ yield ( 3.3-fold). These results were similar to those obtained for MDC6521, and they indicated that DMSO could inhibit $\mathrm{H}_{2}$ production depending on its concentration [26]. $\mathrm{H}_{2}$ production by the other strain-Rh. sphaeroides MDC6521 is more sensitive to the inhibitors action. DPI, DNP and CCCP irreversibly repress the $\mathrm{H}_{2}$ production; however DMSO and Met reversibly inhibit this process. When Met and DMSO was added into the growth medium, $\mathrm{H}_{2}$ started to be produced after 144-168 h (not shown) growth, probably, according to the recovery of enzyme activity.

\section{Effects of various inhibitors for enzymes on ATPase activity of $R h$. sphaeroides membrane vesicles}

The $\mathrm{F}_{\mathrm{O}} \mathrm{F}_{1}$-ATPase activity of $R h$. sphaeroides MDC6522 membrane vesicles was analyzed in the presence of inhibitors to reveal the role of ATPase in $\mathrm{H}_{2}$ production. The $\mathrm{F}_{\mathrm{O}} \mathrm{F}_{1}$-ATPase of purple bacteria belongs to F-type ATPase [36]. The membrane vesicles of bacteria, grown in the absence of inhibitors, demonstrated definite ATPase activity. By addition of $0.2 \mathrm{mM} \mathrm{N}, N^{\prime}$ dicyclohexylcarbodiimide (DCCD) ATPase activity was suppressed $\sim 2$-fold ( $<<0.01$ ) (not shown). Low concentrations of DPI and DMSO did not affect the enzyme activity, whereas CCCP $(2 \mu \mathrm{M})$ stimulated ATPase activity on $10 \%$ (Fig. 6). Similar data were obtained by the addition of DNP (not shown) and Met (0.5 and $1 \mathrm{mM}$ ), enhancing this enzyme activity on $~ 40-45 \%$ (see Fig. 6). This effect can be attributed to the $\mathrm{F}_{\mathrm{O}} \mathrm{F}_{1}$-ATPase, because DCCD specifically inhibits the $\mathrm{F}_{\mathrm{O}} \mathrm{F}_{1}$-ATPase in various bacteria [31,32]. It is possible, that these effects might be a result of inhibitors effect on ATPase via binding with enzyme and changing its activity, or on $E_{h}$, which can regulate the $\mathrm{F}_{\mathrm{O}} \mathrm{F}_{1}$-ATPase activity. 


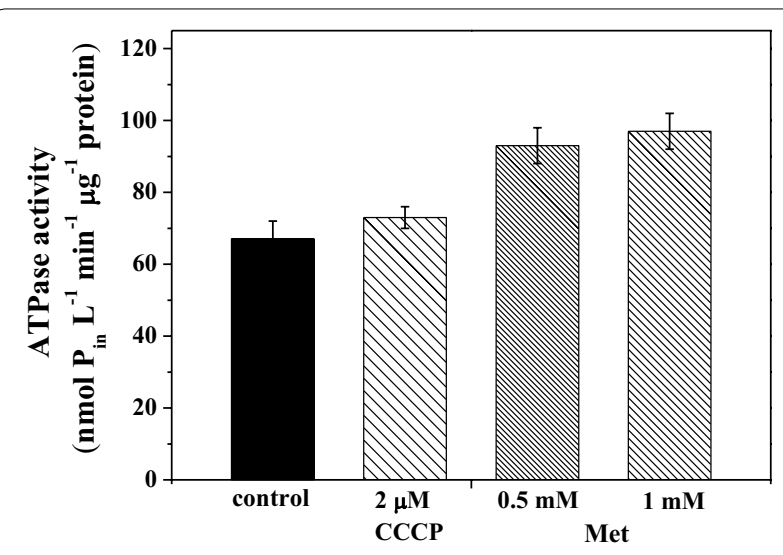

Fig. 6 ATPase activity of Rh. sphaeroides MDC6522 membrane vesicles, which was calculated by colorimetric determination of liberation of inorganic phosphate $\left(\mathrm{P}_{\text {in }}\right)$ per time and protein upon ATP adding (see "Methods")

\section{Discussion}

Purple non-sulfur bacteria are the most studied photosynthetic bacteria due to their demonstrated high $\mathrm{H}_{2}$ production yield. Two enzymes-nitrogenase and hydrogenase are involved in $\mathrm{H}_{2}$ metabolism in these bacteria. In the anaerobic nitrogen-limited conditions, during bacterial non-oxygenic photosynthesis, organic carbon sources are oxidized to $\mathrm{CO}_{2}$, protons and electrons. $\mathrm{H}^{+}$ can be recombined by a nitrogenase to produce $\mathrm{H}_{2}$ using energy of ATP, which is generated by the $\mathrm{F}_{\mathrm{O}} \mathrm{F}_{1}$-ATPase during the work of photosynthetic apparatus [2, 7, 8]. The participation of hydrogenase in $\mathrm{H}_{2}$ production is also suggested under the other-nitrogen-excess conditions $[1,25,26]$. But appropriate mechanisms of photofermentation and $\mathrm{H}_{2}$ production depending on conditions are not clear yet. Thereby, two aspects of photofermentative $\mathrm{H}_{2}$ production by $R h$. sphaeroides are interesting: 1st-type of enzyme (nitrogenase or hydrogenase), which is responsible for $\mathrm{H}_{2}$ production depending on the nitrogen-limited or nitrogen-excess conditions, and the relationship between these enzymes; and 2nd-a role of the $\mathrm{F}_{\mathrm{O}} \mathrm{F}_{1}$-ATPase in photofermentation and $\mathrm{H}_{2}$ production by $R h$. sphaeroides.

In this study the comparative analysis of protonophores and various inhibitors low concentrations effects on photofermentative $\mathrm{H}_{2}$ production during $R h$. sphaeroides MDC6522 anaerobic growth in nitrogen-limited and nitrogen-excess conditions are presented. Two possible pathways of $\mathrm{H}_{2}$ generation in nitrogen-limited and nitrogen-excess conditions can be suggested (Fig. 7). $\mathrm{H}_{2}$ production from various carbon sources by purple bacteria is observed in anaerobic conditions under illumination (see Fig. 1). $\mathrm{H}_{2}$ yield of $R h$. sphaeroides control cells during growth up to $72 \mathrm{~h}$ in nitrogen-excess anaerobic conditions was $\sim 1$-2-fold lower in comparison with nitrogen-limited conditions (see Fig. 5). In nitrogenexcess conditions nitrogenase catalyzes the reduction of $\mathrm{N}_{2}$ to ammonia according to the reaction: $\mathrm{N}_{2}+8 \mathrm{H}^{+}+$ $8 \mathrm{e}^{-}+16 \mathrm{ATP} \rightarrow 2 \mathrm{NH}_{3}+\mathrm{H}_{2}+16 \mathrm{ADP}+16 \mathrm{P}_{\mathrm{i}}$, which leads to the generation of $1 \mathrm{~mol} \mathrm{H}_{2}$ per mole of $\mathrm{N}_{2}$ fixed $[4,7,8]$. However, in nitrogen-limited conditions nitrogenase catalyzes reduction of protons to $\mathrm{H}_{2}$ according to the reaction: $8 \mathrm{H}^{+}+8 \mathrm{e}^{-}+16 \mathrm{ATP} \rightarrow 4 \mathrm{H}_{2}+16 \mathrm{ADP}+16$ Pi. Thereby, in these conditions 4 times more $\mathrm{H}_{2}$ can be produced.

In the presence of protonophores and Met $\mathrm{H}_{2}$ yield has decreased $\sim 5-8$-folds. It is known, that CCCP and DNP are protonophores, which dissipate the $\Delta p$ and inhibit the synthesis of ATP via the $\mathrm{F}_{\mathrm{O}} \mathrm{F}_{1}$-ATPase [14-17, 35]. Indeed, these protonophores can inhibit nitrogenasedependent photofermentative $\mathrm{H}_{2}$ production by inhibiting the synthesis of ATP (Fig. 7a). The mechanisms of the Met inhibition are not clear yet, but it is known, that Met as a low-range electron acceptor can interact with the low potential electron carriers (Fd, flavodoxin) in photosynthetic electron transfer chain. The inhibitory effects of Met on the $\mathrm{H}_{2}$ yield in $R h$. sphaeroides may be associated with dysfunction of the photosynthetic electron transport chain (Fig. 7a). Met penetrates into the bacterial cell through passive diffusion, where its nitro-group is reduced to reactive cytotoxic nitro-radicals by reduced Fd $[37,38]$. Fd works as electron acceptors of nitrogenase, hydrogenase and other enzymes in anaerobic bacteria. It is known, that the selective toxicity of Met for anaerobic microorganisms is due to the redox potential of their electron transport components, which are sufficiently negative to reduce the nitro-group of Met [38].

Reversibility of hydrogenases is suggested for various chemotropic and phototrophic bacteria [1, 3, 12, 13, 39], so hydrogenase in $R h$. sphaeroides might be bidirectional involved in $\mathrm{H}_{2}$ production (Fig. 7b). The complete inhibition of $\mathrm{H}_{2}$ production by $R h$. sphaeroides was observed in the presence of 1-2 $\mu \mathrm{M}$ DPI, whereas DPI's solvent-DMSO did not significantly affect $\mathrm{H}_{2}$ yield. The results with the inhibitory effects of DPI on $\mathrm{H}_{2}$ yield in $R h$. sphaeroides provide a new evidence of involvement of hydrogenase in $\mathrm{H}_{2}$ production by these bacteria.

Then, to understand the role of ATPase in $\mathrm{H}_{2}$ production by $R h$. sphaeroides the $\mathrm{F}_{\mathrm{O}} \mathrm{F}_{1}$-ATPase activity of bacterial membrane vesicles was investigated. Low concentrations of DPI and DMSO did not affect the enzyme activity, whereas CCCP $(2 \mu \mathrm{M})$ and Met $(0.5-1 \mathrm{mM})$ enhanced ATPase activity on $10 \%$ and $\sim 40-45 \%$, respectively. These effects might be a result of inhibitors effect on ATPase via binding with the enzyme and changing its activity. Indeed, CCCP suppressed transfer of $\mathrm{H}^{+}$by whole cells of $R h$. sphaeroides, as shown before 


\section{a}

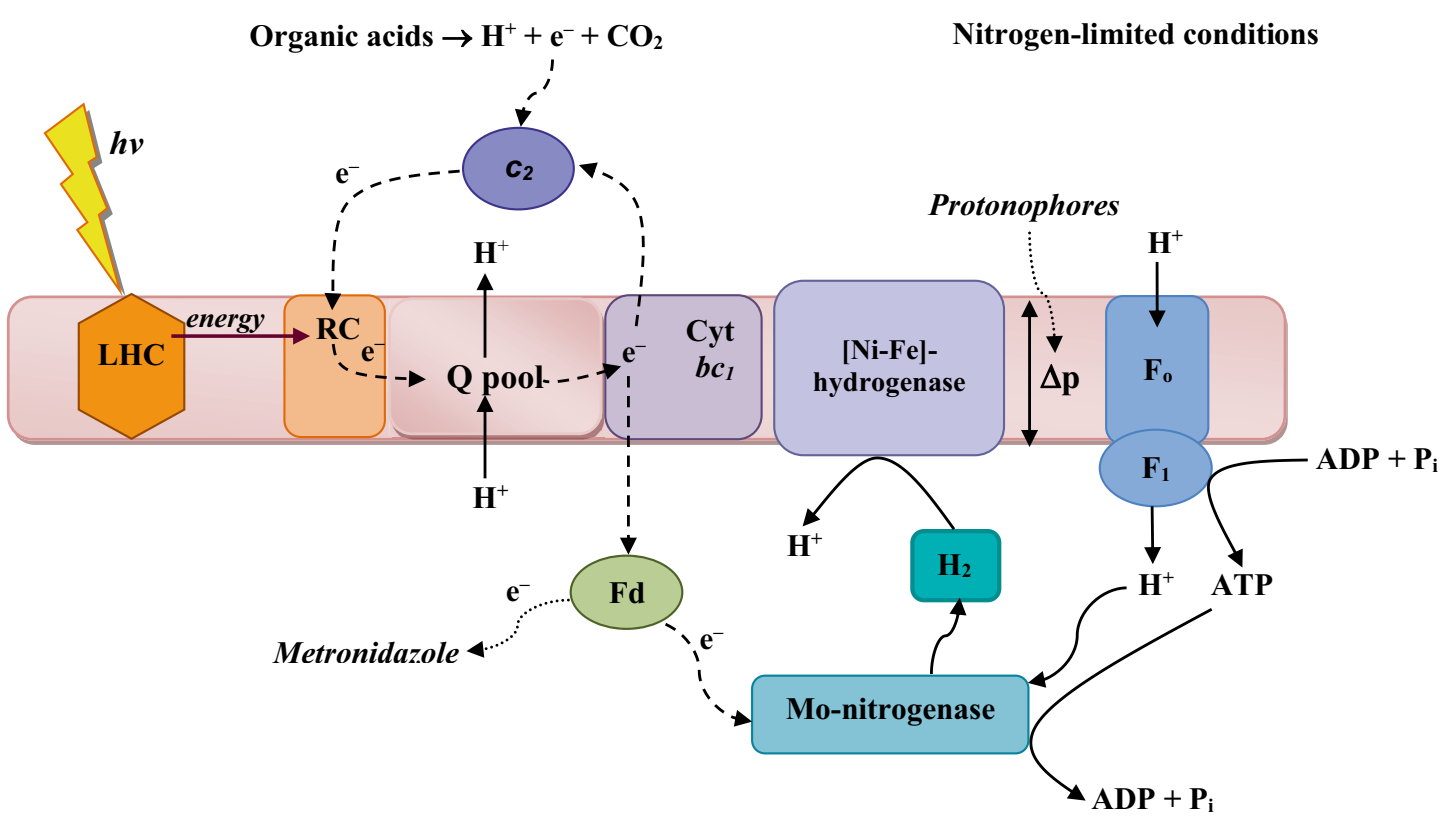

b

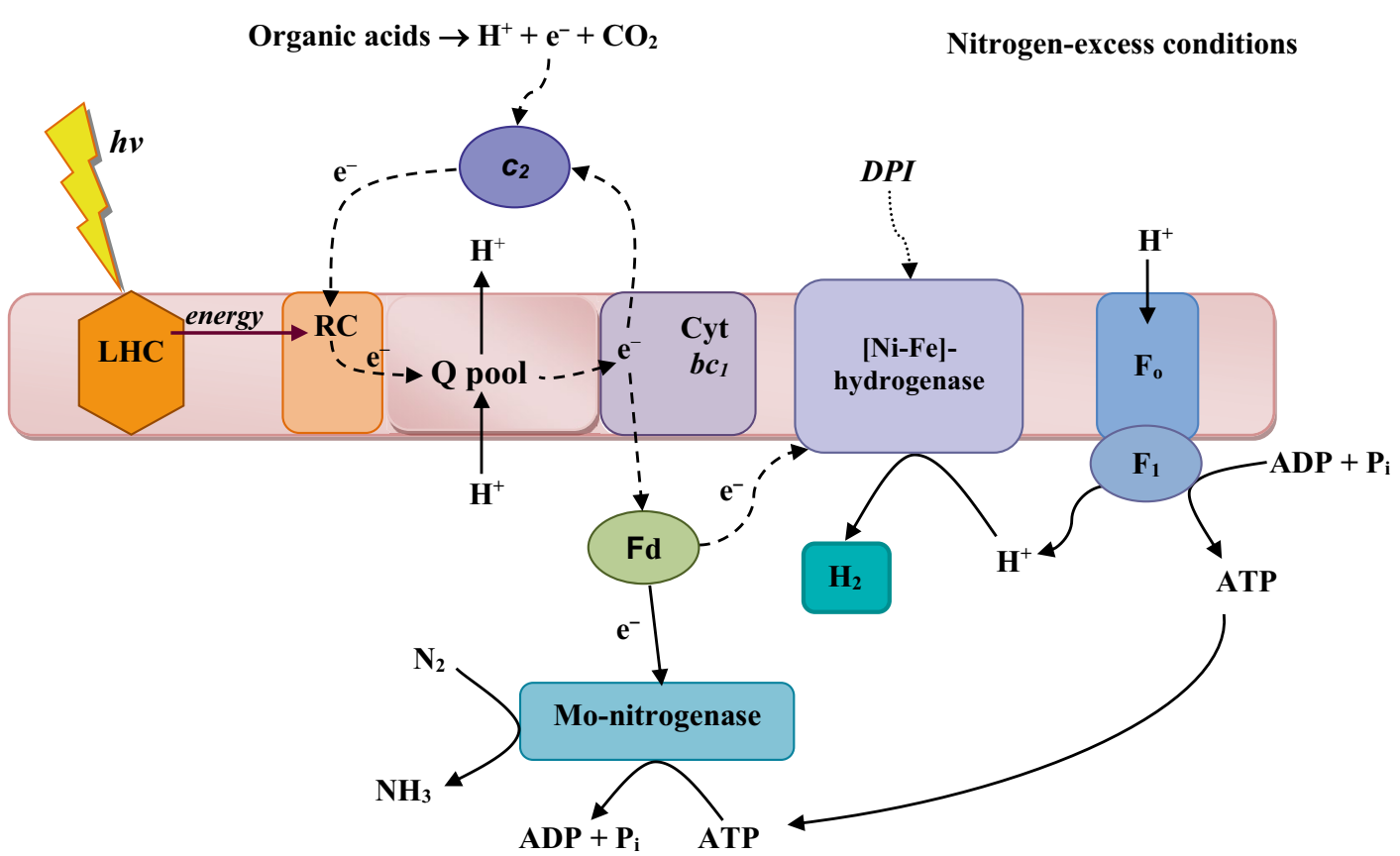

Fig. 7 Proposed pathways involved in $\mathrm{H}_{2}$-metabolism in Rh. sphaeroides in nitrogen-limited (a) and nitrogen-excess (b) conditions. LHC light harvesting complex, $R C$ reaction center, $Q$ ubiquinone, $F d$ ferredoxin, Cyt cytochrome, $\Delta p$ proton motive force, $P_{i}$ inorganic phosphate. See the text

[40], which confirms the role of the $\Delta p$ in the activity of enzymes responsible for $\mathrm{H}^{+}$transfer and $\mathrm{H}_{2}$ production.

Thus, two possible routes of $\mathrm{H}_{2}$ production by $R h$. sphaeroides can be suggested (Fig. 7). Oxidation of organic acids generates electrons, which are passed through various photosynthetic electron transfer carriers to Fd, and protons, which are pumped through the membrane generating a $\Delta p$. The latter derives the synthesis of ATP from ADP and inorganic phosphate $\left(\mathrm{P}_{\mathrm{i}}\right)$ via the $\mathrm{F}_{\mathrm{O}} \mathrm{F}_{1}$-ATPase. Then Fd and ATP are used to generate $\mathrm{H}_{2}$ 
via nitrogenase. Protonophores used can inhibit nitrogenase-dependent $\mathrm{H}_{2}$ production by suppressing synthesis of ATP, whereas the Met can interact with Fd in photosynthetic electron transfer chain and can work as an alternative electron acceptor, instead of nitrogenase.

\section{Conclusions and significance}

The data have shown low concentration or concentration dependent effects of protonophores and nitrogenise and hydrogenase inhibitors on photofermentative $\mathrm{H}_{2}$ production by $R h$. sphaeroides in nitrogen-limited and nitrogen-excess conditions. The results obtained are significant to understand the relationship between nitrogenase, hydrogenase and the $\mathrm{F}_{\mathrm{O}} \mathrm{F}_{1^{-}}$ ATPase and their roles during photofermentation and $\mathrm{H}_{2}$ production in $R h$. sphaeroides. The relationship if any can be considered as a novel property of these enzymes. Importantly, the relationship depends on the nitrogen-excess and nitrogen-limited conditions. Thus, protonophores and nitrogenase and hydrogenase various inhibitors at different concentrations can be applied in the development of scale-up $\mathrm{H}_{2}$ production biotechnology, for biomass and energy production using purple bacterial cells.

\section{Methods}

\section{Bacterial strain and growth conditions}

In the present work we used $R h$. sphaeroides strain MDC6522 (Microbial Depository Center, Armenia, WDCM803), which was isolated from Jermuk mineral waters ( $\left.\mathrm{pH} 6.5-8.5,57-64{ }^{\circ} \mathrm{C}\right)$ in Armenian mountains $[9,30]$. Bacteria were grown in batch culture anaerobically upon illumination $\left(\sim 36 \mathrm{~W} \mathrm{~m}^{-2}\right)$ in Ormerod medium with succinate as a carbon source and yeast extract as a nitrogen source as described previously [9, 30, 31]. The growth of bacterial culture was recorded by changes in optical density $\left(\mathrm{OD}_{660}\right)$ using a Spectro UV-Vis Auto spectrophotometer (Labomed, USA), and by determining DW of bacterial biomass, which was correlated with $\mathrm{OD}_{660}$ according the equation: $\mathrm{DW}$ $\left(\mathrm{g} \mathrm{L}^{-1}\right)=\mathrm{OD}_{660} \times 0.48$. The specific growth rate was calculated, as described previously $[9,26,31]$.

In order to create conditions of nitrogen source limitation, the media was supplied with yeast extract $\left(2 \mathrm{~g} \mathrm{~L}^{-1}\right)$; whereas to create nitrogen-excess conditions the concentration of yeast extract was increased 2.5-fold (the media was supplied with $5 \mathrm{~g} \mathrm{~L}^{-1}$ yeast extract). Yeast extracts contain various amino acids, vitamins and other growth stimulating compounds and therefore it can be used as a component of growth media for the cultivation of various microorganisms [30, 41].

The concentrations of DPI and CCCP added into the growth medium ranged from 0.5 to $2 \mu \mathrm{M}$; DNP-from 5 to $50 \mu \mathrm{M}$; Met-from 0.1 to $2 \mathrm{mM}$, DMSO-from 1 to $10 \mathrm{mM}$.

\section{Determinations of $\mathrm{pH}, E_{h}$ and $\mathrm{H}_{2}$ yield}

The initial $\mathrm{pH}$ of the culture medium was maintained to $7.0 \pm 0.1$ by $0.1 \mathrm{M} \mathrm{NaOH}$ or $0.1 \mathrm{M} \mathrm{HCl}$ and determined at certain time intervals $(0-96 \mathrm{~h})$ by a $\mathrm{pH}$-meter (HANNA Instruments, Portugal) with selective $\mathrm{pH}$ electrode, as described [9, 25, 31].

The medium $E_{h}$ was determined during Rh. sphaeroides growth using a pair of redox (platinum $(\mathrm{Pt})$ and titaniumsilicate $(\mathrm{Ti}-\mathrm{Si}))$ and reference $(\mathrm{Ag} / \mathrm{AgCl})$ electrodes, as described before [9, 26, 31]. Note Ti-Si electrode measures the overall $E_{h}$, whereas Pt electrode (sensitive to $\mathrm{O}_{2}$ and $\mathrm{H}_{2}$ ) under anaerobic conditions detects only $\mathrm{H}_{2}$ [30, 32]. $E_{h}$ kinetics determined using redox electrodes during culture growth gives information about main redox processes and also $\mathrm{H}_{2}$ generation [31,32]. The $\mathrm{H}_{2}$ yield was evaluated by the drop of $E_{h}$ to low negative values using correlation between $E_{h}$ change and $\mathrm{H}_{2}$ evolution and was expressed in $\mathrm{mmol} \mathrm{H}_{2}(\mathrm{~g} \mathrm{DW})^{-1}[9,31]$ :

$$
\mathrm{H}_{2} \text { yield }=\frac{\text { Amount of produced } \mathrm{H}_{2}\left(\mathrm{mmol} \mathrm{L}^{-1}\right)}{\text { Dry weight }\left(\mathrm{g} \mathrm{L}^{-1}\right)} \text {. }
$$

This determination of $\mathrm{H}_{2}$ is close to the method with Clark-type electrode employed by other authors [42, 43]. $\mathrm{H}_{2}$ generation was confirmed by the chemical method, as described $[26,44]$.

\section{ATPase activity assay}

ATPase activity of Rh. sphaeroides bacterial membrane vesicles was determined by the liberation of inorganic phosphate $\left(\mathrm{P}_{\text {in }}\right)$ in the reaction with ATP by the spectrophotometric method, as described [31, 32], and it was expressed in nmol $\mathrm{P}_{\text {in }}$ per $\mathrm{L}$ per $\mu \mathrm{g}$ protein in $1 \mathrm{~min}$. Membrane vesicles were prepared by the method, as described previously [26, 31]. For inhibitors effects studies, the membrane vesicles were incubated with inhibitors for $10 \mathrm{~min}$.

\section{Reagents and data processing}

CCCP, Met, DPI, DNP, DMSO, DCCD, ATP were obtained from Sigma, Aldrich (USA); yeast extract was purchased from Carl Roth GmbH (Germany) and succinic acid was obtained from Unichem (China). The other reagents of analytical grade were used in this study.

Each experiment was repeated three times to determine deviations, which are displayed as error bars on figures. The standard errors were calculated and Student criteria (p) were employed to validate the difference in average data between different series of experiments, as described previously $[26,31]$. 


\section{Abbreviations}

CCCP: carbonyl cyanide m-chlorophenylhydrazone; DCCD: N,N'-dicyclohexylcarbodiimide; DMSO: dimethylsulphoxide; DNP: 2,4-dinitrophenol; DPI: diphenyleneiodonium; DW: dry weight; $E_{h}$ : redox potential; Met: metronidazole; OD: optical density; TCA: tricarboxylic acid cycle; $\Delta p$ : proton motive force.

\section{Authors' contributions}

LG performed the cultivation and biohydrogen production study in $R h$ sphaeroides. HS carried out preparation of membrane vesicles and ATPase activity assay. LG and HS interpreted the obtained data and drafted the manuscript. AT supervised and coordinated the research, reviewed and edited the manuscript. All authors have read and approved the manuscript.

\section{Author details}

1 Department of Microbiology \& Microbes and Plants Biotechnology, Biology Faculty, Yerevan State University, 1 A. Manoukian Str., 0025 Yerevan, Armenia.

2 Department of Biophysics, Biology Faculty, Yerevan State University, 1 A. Manoukian Str., 0025 Yerevan, Armenia.

\section{Acknowledgements}

The authors thank Dr. L. Hakobyan for participation in preparation of the bacterial membrane vesicles. This study was supported by Research grant from the State Committee of Science, Ministry of Education and Science of Armenia, to AT (13-1F002) and by Research grant from the Armenian National Science and Education Fund (ANSEF), based in New York, USA, to LG (NS-Biotechnology-3777).

\section{Compliance with ethical guidelines}

\section{Competing interests}

The authors declare that they have no competing interests.

Received: 29 May 2015 Accepted: 22 August 2015

Published online: 04 September 2015

\section{References}

1. Trchounian A. Mechanisms for hydrogen production by different bacteria during mixed-acid and photo-fermentation and perspectives of hydrogen production biotechnology. Crit Rev Biotechnol. 2015;35:103-13.

2. Basak N, Jana AK, Das D, Saiki D. Photofermentative molecular biohydrogen production by purple-non-sulfur (PNS) bacteria in various modes: the present progress and future perspective. Int J Hydrog Energy. 2014:39:6853-71.

3. Trchounian K, Trchounian A. Hydrogen production from glycerol by Escherichia coli and other bacteria: an overview and perspectives. Appl Energy. 2015;156:174-84.

4. Momirlan M, Veziroglu TN. The properties of hydrogen as fuel tomorrow in sustainable energy system for a cleaner planet. Int J Hydrog Energy. 2005;33:795-802.

5. Hallenbeck PC, Abo-Hashesh M, Ghosh D. Strategies for improving biological hydrogen production. Bioresour Technol. 2012;110:1-9.

6. Dutta D, De D, Chaudhuri S, Bhattacharya SK. Hydrogen production by cyanobacteria. Microb Cell Fact. 2005;4:36.

7. Androga DD, Özgür E, Eroglu I, Gündüz U, Yücel M. Photofermentative hydrogen production in outdoor conditions. In: Minic D, editor. Hydrogen energy — challenges and perspectives. In Tech; 2012. p. 77-120.

8. Gabrielyan L, Trchounian A. Purple bacteria and cyanobacteria as potential producers of molecular hydrogen: an electrochemical and bioenergetic approach. In: Trchounian A, editor. Bacterial membranes. Kerala: Research Signpost; 2009. p. 233-73.

9. Sargsyan H, Gabrielyan L, Hakobyan L, Trchounian A. Light-dark duration alternation effects on Rhodobacter sphaeroides growth, membrane properties and bio-hydrogen production in batch culture. Int J Hydrog Energy. 2015:40:4084-91.

10. Seefeldt LC, Yang Z-Y, Duval S, Dean DR. Nitrogenase reduction of carboncontaining compounds. Biochim Biophys Acta. 2013;1827:1102-11.
11. Kars $K$, Gündüz U. Towards a super $\mathrm{H}_{2}$ producer: improvements in photofermentative biohydrogen production by genetic manipulations. Int J Hydrog Energy. 2010;35:6646-56.

12. Das D, Dutta T, Nath K, Kotay ShM, Das AK, Veziroglu TN. Role of Fe-hydrogenase in biological hydrogen production. Curr Sci. 2006;90:1627-37.

13. Kufryk $\mathrm{G}$. Advances in utilizing cyanobacteria for hydrogen production. Adv Microbiol. 2013;3:60-8.

14. Bottomley PJ, Stewart WDP. ATP and nitrogenase activity in nitrogenfixing heterocystous blue-green algae. New Phytol. 1977;79:625-38.

15. Smith RL, Van Baalen C, Tabita FR. Alteration of the Fe protein of nitrogenase by oxygen in the cyanobacterium Anabaena sp. strain CA. J Bacteriol. 1987;169:2537-42.

16. Weisshaar H, Böger P. Nitrogenase activity of the non-heterocystous cyanobacterium Phormidium foveolarum. Arch Microbiol. 1983;136:270-4.

17. Daday A, Platz RA, Smith GD. Anaerobic and aerobic hydrogen gas formation by the blue-green alga Anabaena cylindrical. Appl Environ Microbiol. 1977;34:478-88.

18. Tetley RM, Bishop NI. The differential action of metronidazole on nitrogen fixation, hydrogen metabolism, photosynthesis and respiration in Anabaena and Scenedesmus. Biochim Biophys Acta. 1979;546:43-53.

19. Bhattacharya J, Singh AK, Singh RKS, Rai AN. Metronidazole as a specific inhibitor of nitrogenase activity in heterocyctous cyanobacterium Nostoc ANTH, an isolate from Anthoceros punctatus. Ind J Microbiol. 2005;45:115-20.

20. Eisbrenner $\mathrm{G}$, Bothe $\mathrm{H}$. Modes of electron transfer from molecular hydrogen in Anabaena cylindrical. Arch Microbiol. 1979;123:37-45.

21. Magnani P, Doussiere J, Lissolo T. Diphenyleneiodonium as an inhibitor for the hydrogenase complex of Rhodobacter capsulatus. Evidence for two distinct electron donor sites. Biochim Biophys Acta. 2000;1459:169-78.

22. Mus F, Cournac L, Cardettini V, Caruana A, Peltier G. Inhibitor studies on non-photochemical plastoquinone reduction and $\mathrm{H}_{2}$ photoproduction in Chlamydomonas reinhardtii. Biochim Biophys Acta. 2005;1708:322-32.

23. Markarian SA, Poladyan AA, Kirakosyan GR, Trchounian AA, Bagramyan KA. Effect of diethylsulphoxide on growth, survival and ion exchange of Escherichia coli. Lett Appl Microbiol. 2002;34:417-21.

24. Yu ZW, Quinn PJ. The modulation of membrane structure and stability by dimethyl sulphoxide. Mol Membr Biol. 1998;15:59-68.

25. Sargsyan H, Gabrielyan L, Trchounian A. Concentration-dependent effects of metronidazole, inhibiting nitrogenase, on hydrogen photoproduction and proton-translocating ATPase activity of Rhodobacter sphaeroides. Int J Hydrog Energy. 2014;39:100-6.

26. Hakobyan L, Gabrielyan L, Trchounian A. Relationship of proton motive force and the $\mathrm{F}_{0} \mathrm{~F}_{1}$-ATPase with bio-hydrogen production activity of Rhodobacter sphaeroides: effects of diphenyleneiodonium, hydrogenase inhibitor, and its solvent dimethylsulphoxide. J Bioenerg Biomembr. 2012;44:495-502

27. Ryzhkina IS, Murtazina LI, Kiseleva YV, Konovalov Al. Properties of supramolecular nanoassociates formed in aqueous solutions of biologically active compounds in low or ultra low concentrations. Rep Acad Sci (Moscow) 2009;428:196-200.

28. Konovalov Al, Ryzhkina IS, Murtazina LI, Kiseleva IV. Forming the nanosized molecular assemblies (nanoassociates) is a key to understand the properties of highly diluted aqueous solutions. Biophysics (Moscow) 2014;59:421-7. (In Russian)

29. Hustede E, Steinbüchel A, Schlegel HG. Relationship between the photoproduction of hydrogen and the accumulation of PHB in non-sulphur purple bacteria. Appl Microb Biotechnol. 1993;39:87-93.

30. Hakobyan L, Gabrielyan L, Trchounian A. Yeast extract as an effective nitrogen source stimulating cell growth and enhancing hydrogen photoproduction by Rhodobacter sphaeroides strains from mineral springs. Int J Hydrog Energy. 2012;37:6519-26.

31. Gabrielyan L, Sargsyan H, Hakobyan L, Trchounian A. Regulation of hydrogen photoproduction in Rhodobacter sphaeroides batch culture by external oxidizers and reducers. Appl Energy. 2014;131:20-5.

32. Poladyan A, Trchounian K, Sawers RG, Trchounian A. Hydrogen-oxidizing hydrogenases 1 and 2 of Escherichia coli regulate the onset of hydrogen evolution and ATPase activity, respectively, during glucose fermentation at alkaline pH. FEMS Microbiol Lett. 2013;348:143-8.

33. Carius $L$, Hädicke $O$, Grammel $H$. Stepwise reduction of the culture redox potential allows the analysis of microaerobic metabolism and photosynthetic membrane synthesis in Rhodospirillum rubrum. Biotechnol Bioeng 2013:110:573-85. 
34. Li X, Dai Z-Z, Wang T-H, Zhang S-L. Enhancement of phototrophic hydrogen production by Rhodobacter sphaeroides ZX-5 using fed-batch operation based on ORP level. Int J Hydrog Energy. 2011;36:12794-802.

35. Skizim NJ, Ananyev GM, Krishnan A, Dismukes GCh. Metabolic pathways for photobiological hydrogen production by nitrogenase- and hydrogenase-containing unicellular cyanobacteria Cyanothece. J Biol Chem. 2011;287:2777-86.

36. Feniouk BA, Junge W. Proton translocation and ATP synthesis by the $F_{0} F_{1}$ ATPase of purple bacteria. In: Hunter CN, Daldal F, Thurnauer MC, Beatty JT, editors. The purple phototrophic bacteria. The Netherlands: Springer Science + Business Media BV; 2009. p. 475-93.

37. Müller M. Reductive activation of nitroimidazoles in anaerobic microorganisms. Biochem Pharmacol. 1986;35:37-41.

38. Wassmann C, Hellberg A, Tannich E, Bruchhaus I. Metronidazole resistance in the protozoan parasite Entamoeba histolytica is associated with increased expression of iron-containing superoxide dismutase and peroxiredoxin and decreased expression of ferredoxin 1 and flavin reductase. J Biol Chem. 1999;274:26051-6.

39. Trchounian K, Poladyan A, Vassilian A, Trchounian A. Multiple and reversible hydrogenases for hydrogen production by Escherichia coli: dependence on fermentation substrate, $\mathrm{pH}$ and $\mathrm{F}_{0} \mathrm{~F}_{1}$-ATPase. Crit Rev Biochem Mol Biol. 2012;47:236-49.
40. Gabrielyan L, Trchounian A. Relationship between molecular hydrogen production, proton transport and the $\mathrm{F}_{0} \mathrm{~F}_{1}$-ATPase activity in Rhodobacter sphaeroides strains from mineral springs. Int J Hydrog Energy. 2009;34:2567-72.

41. Kalil MS, Alshiyab HSS, Wan Yusoff WM. Media improvement for hydrogen production using C. acetobutylicum NCIMB 13357. Am J Appl Sci. 2009;6:1158-68

42. Eltsova ZA, Vasilieva LG, Tsygankov AA. Hydrogen production by recombinant strains of Rhodobacter sphaeroides using a modified photosynthetic apparatus. Appl Biochem Microbiol. 2010;46:487-91.

43. Noguchi K, Riggins DP, Eldahan KC, Kitko RD, Slonczewski JL. Hidrogenase-3 contributes to anaerobic acid resistance of Escherichia coli. PLoS One. 2010;5:1-7.

44. Maeda T, Wood TK. Formate detection by potassium permanganate for enhanced hydrogen production in Escherichia coli. Int J Hydrog Energy. 2008;33:2409-12.

\section{Submit your next manuscript to BioMed Central and take full advantage of:}

- Convenient online submission

- Thorough peer review

- No space constraints or color figure charges

- Immediate publication on acceptance

- Inclusion in PubMed, CAS, Scopus and Google Scholar

- Research which is freely available for redistribution

Submit your manuscript at

www.biomedcentral.com/submit

C Biomed Central 